\title{
Endobronchial valves in severe emphysematous patients: CT evaluation of lung fissures completeness, treatment radiological response and quantitative emphysema analysis*
}

Valvas endobrônquicas em pacientes com enfisema grave: avaliação por TC da completude das fissuras pulmonares, resposta radiológica ao tratamento e análise quantitativa do enfisema

\author{
Marcel Koenigkam-Santos ${ }^{1}$, Wagner Diniz de Paula ${ }^{2}$, Daniela Gompelmann ${ }^{3}$, Hans-Ulrich Kauczor ${ }^{4}$, \\ Claus Peter Heussel ${ }^{5}$, Michael Puderbach ${ }^{6}$
}

Abstract Objective: To evaluate lung fissures completeness, post-treatment radiological response and quantitative CT analysis (QCTA) in a population of severe emphysematous patients submitted to endobronchial valves (EBV) implantation. Materials and Methods: Multi-detectors CT exams of 29 patients were studied, using thin-section low dose protocol without contrast. Two radiologists retrospectively reviewed all images in consensus; fissures completeness was estimated in $5 \%$ increments and post-EBV radiological response (target lobe atelectasis/volume loss) was evaluated. QCTA was performed in pre and post-treatment scans using a fully automated software. Results: CT response was present in 16/29 patients. In the negative CT response group, all 13 patients presented incomplete fissures, and mean oblique fissures completeness was $72.8 \%$, against $88.3 \%$ in the other group. QCTA most significant results showed a reduced post-treatment total lung volume (LV) (mean $542 \mathrm{ml}$ ), reduced EBV-submitted LV (700 ml) and reduced emphysema volume $(331.4 \mathrm{ml})$ in the positive response group, which also showed improved functional tests. Conclusion: EBV benefit is most likely in patients who have complete interlobar fissures and develop lobar atelectasis. In patients with no radiological response we observed a higher prevalence of incomplete fissures and a greater degree of incompleteness. The fully automated QCTA detected the post-treatment alterations, especially in the treated lung analysis.

Keywords: Emphysema; Collapse therapy; Computed tomography.

Resumo Objetivo: Avaliar a completude das fissuras, resposta radiológica ao tratamento e análise quantitativa por TC (AQTC) em população de pacientes com enfisema grave submetidos ao implante de valvas endobrônquicas (VEB). Materiais e Métodos: Foram estudados exames de TC multidetectores de 29 pacientes, realizados com protocolo de baixo dose, cortes finos, sem contraste. Dois radiologistas revisaram, retrospectivamente, os exames em consenso. A completude das fissuras foi estimada em escala de $5 \%$ e a resposta radiológica (atelectasia/perda volumétrica do lobo alvo) foi avaliada. AQTC foi realizada nos exames pré e pós-tratamento utilizando programa completamente automático. Resultados: Resposta radiológica positiva foi vista em 16/29 pacientes. Os 13 pacientes sem resposta à TC apresentavam fissuras incompletas e completude média das fissuras obliquas de $72,8 \%$, contra $88,3 \%$ no outro grupo. Os resultados mais significativos da AQTC mostraram redução do volume pulmonar (VP) total (média de $542 \mathrm{ml}$ ), VP tratado $(700 \mathrm{ml})$ e volume de enfisema $(331,4 \mathrm{ml})$ no grupo com resposta positiva, que também apresentou melhora nos testes funcionais. Conclusão: 0 benefício das VEB é maior em pacientes com fissuras completas e que desenvolvem atelectasia lobar. Nos pacientes sem resposta radiológica encontramos maior prevalência de fissuras incompletas e grau de incompletude das fissuras. Nossa AQTC automática detectou as alterações pós-tratamento, principalmente considerado a análise do pulmão tratado.

Unitermos: Enfisema; Terapia de colapso pulmonar; Tomografia computadorizada.

Koenigkam-Santos M, Paula WD, Gompelmann D, Kauczor HU, Heussel CP, Puderbach M. Endobronchial valves in severe emphysematous patients: CT evaluation of lung fissures completeness, treatment radiological response and quantitative emphysema analysis. Radiol Bras. 2013 Jan/Fev;46(1):15-22.

* Study developed at the Chest Clinic (Thoraxklinik), University of Heidelberg, Heidelberg, Germany.

1. MD PhD, Radiologist, Attending Physician at Hospital das Clínicas da Faculdade de Medicina de Ribeirão Preto, Universidade de São Paulo (HCFMRP-USP), Ribeirão Preto, SP, Brazil, Post Doctoral Fellow at University of Heidelberg, Heidelberg, Germany.

2. MD, Radiologist, Attending Radiologist at Brasília University Hospital, University of Brasília (UnB), Brasília, DF, Brazil.

3. MD, Attending Physician at Department of Pneumology and
Respiratory Medicine of the Chest Clinic (Thoraxklinik), University of Heidelberg, Heidelberg, Germany.

4. Prof Dr, Radiologist, Chairman of the Department of Diagnostic and Interventional Radiology, University of Heidelberg, Heidelberg, Germany.

5. Prof Dr, Radiologist, Chief of the Department of Diagnostic and Interventional Radiology with Nuclear Medicine of the Chest Clinic (Thoraxklinik), University of Heidelberg, Heidelberg, Germany.
6. MD PhD, Radiologist, Attending Physician (Oberarzt) at Department of Diagnostic and Interventional Radiology with Nuclear Medicine of the Chest Clinic (Thoraxklinik), University of Heidelberg, Heidelberg, Germany.

Corresponding author: Marcel Koenigkam Santos. Im Neuenheimer Feld 370, 69120 Heidelberg, Germany. E-mail: marcelk46@yahoo.com.br / marcelk46@usp.br.

Received September 21, 2012. Accepted after revision December 17, 2012 


\section{INTRODUCTION}

Emphysema affects $1.8 \%$ of the population worldwide and is characterized by progressive deterioration in pulmonary function, with exercise limitation, disabling dyspnea and decrease in quality of life. Besides lung transplantation as a treatment option for end-stage emphysema patients, bullectomy and lung volume reduction surgery (LVRS) were developed as alternative of surgical palliation of symptoms for severe emphysematous patients, and demonstrated to improve symptoms, lung function, exercise tolerance and survival ${ }^{(\mathbf{1})}$. However, only a restricted group of patients are suited for these procedures, which are associated with high morbidity and mortality. More recently, several bronchoscopic lung volume reduction (BLVR) strategies have been developed, and they also achieved improvements in lung function and exercise capacity, but with lower treatment-associated morbidity and mortality ${ }^{(2)}$. Within the bronchoscopic options, the use of the removable one-way flow endobronchial valves (EBV) to obtain the collapse of the most diseased target lobe is advantageous, being easy to employ and offering the possibility of temporal application. EBV has been used worldwide, and also in Brazil some centers have described their experience ${ }^{(3)}$.

Imaging methods have an important role in the evaluation of patients suitable to lung volume reduction therapies. Highresolution computed tomography (HRCT) is used not only to identify chronic obstructive pulmonary disease (COPD) patients with predominant emphysematous disease, but also to characterize emphysema degree and distribution. After treatment, CT is used to monitor response, and in the case of EBV, to certify the valves adequate position, exclude procedure-related complications and evaluate for the presence and degree of collapse (atelectasis) of the targeted lobe. More recently, it has been demonstrated that EBV benefit is most likely in patients with heterogeneous emphysema who have complete interlobar fissures and in those which lobar atelectasis have occurred $^{(4,5)}$

The objective of this study was to retrospectively evaluate CT exams of a popu- lation of severe emphysematous patients submitted to EBV implantation. We evaluated the degree of lung fissures completeness in the treated lungs. Post-treatment scans were reviewed for the presence of positive radiological response. Quantitative CT analysis (QCTA) of emphysema was done in pre and post-treatment exams and its results were correlated with both the CT visual analyses and pulmonary functional tests (PFTs).

\section{MATERIALS AND METHODS}

\section{Patients}

Twenty-nine patients (52\% male, average 63 years) submitted to EBV implantation in the year of 2010 were enrolled in this study. All patients suffered from severe COPD (GOLD 3 or 4) and presented heterogeneous emphysema in the HRCT. Indication to EBV implantation followed criteria mostly used as proposed by Copper et al. and posteriorly modified by the NETT and VENT study groups ${ }^{(5-7)}$. Patients were designated with a target lobe suitable to EBV implantation after routine consensus reading by the attending radiology and pneumology groups. Informed consent for scientific evaluation of data was obtained from all patients prior to scanning.

\section{CT scans}

All volumetric scans were obtained on a four-slice multi-detectors CT (MDCT) scanner (Somatom Volume Zoom; Siemens Medical Solutions, Germany), using a thinsection low-dose protocol, with $1.25 \mathrm{~mm}$ collimation and $1.0 \mathrm{~mm}$ increment, B40 reconstruction algorithm, $120 \mathrm{kVp}$ tube tension and $70 \mathrm{~mA}$ tube current, without intravenous administration of iodinated contrast agent. Images were acquired from upper abdomen to thorax apices during end-inspiration breath-hold.

\section{Images evaluation}

Two chest radiologists retrospectively reviewed the MDCT images of all patients in consensus, before and after EBV implant, blinded for treatment clinical outcome and PFTs results, in a dedicated workstation with multiplanar reformation (MPR) capability. Interlobar fissures of the lungs submitted to EBV implantation were analyzed visually in the pre-treatment scans, using the standard lung window settings (level: $-600 \mathrm{HU}$, width: $1600 \mathrm{HU}$ ). For the purpose of the semi quantitative analysis, the oblique fissures were segmented as follows: on the right side, the oblique fissure was divided in superior and inferior halves, with the horizontal fissure as the landmark for this segmentation; on the left side, the oblique fissure was divided into apical, middle and basal thirds. Completeness of the horizontal fissure and all defined segments of the right and left oblique fissures were estimated in 5\% increments. Then, for the oblique fissures, a mean value of completeness was calculated. Post-treatment exams were selected between 1 and 3 months after implantation of the last valve (average 63 days), considering that some patients had EBV implanted or manipulated in more than one bronchoscopy session (misplaced valves, new additional valves in middle lobe bronchi after initial implants in right upper lobe). In all control exams considered to evaluation, the valves were adequately positioned and no signs of significant complication were present. A positive radiological response to EBV implantation was assigned when a complete or partial collapse (lobar or sublobar atelectasis) of the target lobe was identified, or when there was segmental or laminar atelectasis but accompanied by evident signs of significant lobar volume loss (fissures, hilum or diaphragm dislocation); therefore in concordance with the routine qualitative evaluation criteria.

\section{Quantitative CT analysis}

QCTA was performed in all 29 patients, using a fully automated in-house software (YACTA), which is able to segment the airways, right and left lungs without the need of any user interference, as previously described $^{(8)}$. An emphysema threshold of -950 HU was used, with an adjacent voxels error correction of -910 HU. QCTA was done in the same thin section MDCT exams that visual analysis was performed on, and the PFTs selected for correlation were also performed preferable in the same or previous/following day (average 1.3 days difference) from the CT scanning. 


\section{Statistical analysis}

Comparisons in the same group, pre and post-treatment, were done using the Wilcoxon test, while comparisons between the groups (positive versus negative CT response) were performed with the MannWhitney and Fischer's exact tests. A $p$ value of $<0.05$ was considered statistically significant.

\section{RESULTS}

Incomplete fissures were found in the lungs submitted to EBV implantation of 22 $(75.9 \%)$ out of 29 patients. All horizontal fissures $(100 \%)$ were incomplete, while the oblique fissures were incomplete in 19 (65.5\%) out of 29 studied lungs, with 11/ $14(78.6 \%)$ right oblique and 8/15 (53.3\%) left oblique incomplete fissures. Regarding the fissures degree of completeness, oblique fissures showed an average percentage of completeness of $77.7 \%$, being $80.3 \%$ for the right side and $74.1 \%$ for the left. The horizontal fissure completeness was in average $60.4 \%$ when considering all 29 patients.

Atelectasis and volume loss after EBV implantation was present in $16(55.2 \%)$ out of 29 patients. Therefore, we defined a group of 13 patients ( $44.8 \%$ ) with negative CT response and other group of $16(55.2 \%)$ patients with positive CT response. Distribution of the fissures completeness for all patients according to the two groups is showed in Table 1. In the group with negative CT response, all $13(100 \%)$ patients presented incomplete oblique and horizontal fissures. In this group, the average completeness of the oblique fissure was $72.8 \%$, considering both right and left fissures. In the group with positive CT response, 9 $(56.3 \%)$ out of 16 patients presented incomplete fissures (oblique or horizontal), but only $6(37.5 \%)$ out of 16 oblique fissures were incomplete. Average completeness of the incomplete oblique fissures in this group was $88.3 \%$. Horizontal fissure completeness was in average $55.6 \%$ in the negative CT group and $67.5 \%$ in the positive CT group. Therefore, the proportion of patients with incomplete fissures was higher in the negative $\mathrm{CT}$ response group $(p=0.0004)$ and the degree of fissures completeness was lower $(p=0.001)$ when

Table 1 Fissures completeness in all 29 patients studied, as determined in a 5\% scale by two chest radiologists in consensus.

\begin{tabular}{|c|c|c|c|}
\hline \multirow[b]{2}{*}{ Negative CT response group } & \multirow[b]{2}{*}{ EBV target lobe } & \multicolumn{2}{|c|}{ Fissure completeness (\%) } \\
\hline & & Oblique & Horizontal \\
\hline 1 & RLL & 80 & 45 \\
\hline 2 & RUL & 50 & 35 \\
\hline 3 & LLL & 40 & n.a. \\
\hline 4 & LLL & 85 & n.a. \\
\hline 5 & RUL / ML & 75 & 60 \\
\hline 6 & LUL & 55 & n.a. \\
\hline 7 & LLL & 58 & n.a. \\
\hline 8 & RUL & 90 & 55 \\
\hline 9 & RUL / ML & 85 & 65 \\
\hline 10 & RUL & 78 & 35 \\
\hline 11 & RUL / ML & 85 & 95 \\
\hline 12 & RUL & 75 & 55 \\
\hline 13 & $\mathrm{RUL} / \mathrm{ML}$ & 90 & 55 \\
\hline \multicolumn{4}{|l|}{ Positive CT response group } \\
\hline $14^{\star}$ & LUL & 100 & n.a. \\
\hline 15 & LLL & 93 & n.a. \\
\hline $16^{*}$ & LUL & 100 & n.a. \\
\hline 17 & RUL / ML & 100 & 70 \\
\hline $18^{*}$ & LLL & 100 & n.a. \\
\hline 19 & LUL & 100 & n.a. \\
\hline $20 *$ & LLL & 100 & n.a. \\
\hline $21 *$ & RUL / ML & 100 & 70 \\
\hline 22 & $\mathrm{RUL} / \mathrm{ML}$ & 90 & 60 \\
\hline $23^{*}$ & LLL & 95 & n.a. \\
\hline 24 & LLL & 82 & n.a. \\
\hline 25 & RUL & 85 & 70 \\
\hline $26 *$ & LLL & 100 & n.a. \\
\hline 27 & LLL & 85 & n.a. \\
\hline 28 & LUL & 100 & n.a. \\
\hline 29 & RUL / ML & 100 & 75 \\
\hline
\end{tabular}

* Complete lobar atelectasis (best response). EBV, endobronchial valves; n.a., not applicable; RUL / LUL, right / left upper lobe; ML, middle lobe; RLL / LLL, right / left lower lobe.

compared to the positive $\mathrm{CT}$ response group. Also, in the positive CT group, 7 out of 16 patients $(43.8 \%)$ presented complete lobar atelectasis (best response), and among these patients, only one did not have a complete oblique fissure (Table 1). Figures 1, 2 and 3 illustrate patients with different fissures status and radiological response to EBV implantation.

QCTA parameters studied comprised the total lung volume (LV), emphysema volume (EV), emphysema index (EI), mean lung density (MLD) and fifteenth percentile (15th). Functional parameters comprised the forced vital capacity (FVC), forced expiratory volume in 1 second (FEV1), Tiffeneau index (FEV1/FVC), pre- dicted residual volume (RV\%) and predicted total lung capacity (TLC\%). Table 2 shows all the QCTA and PFTs values (mean $\pm \mathrm{SD}$ ) evaluated. When the whole group of 29 patients was considered, we did not find differences in the functional parameters between pre and post-treatment evaluations; but the QTCA showed a post-treatment decrease in total LV (both lungs, mean reduction of $385 \mathrm{ml}, 5.5 \% ; p=0.001$ ), and also reduction of the EBV submitted LV (one lung, mean $444.7 \mathrm{ml}, 12.7 \% ; p=$ $0.0001)$ and EV (mean $190 \mathrm{ml}, 11.2 \% ; p=$ 0.022). When the negative and positive CT groups were considered, we did not find significant differences between the groups concerning the pre-treatment functional 


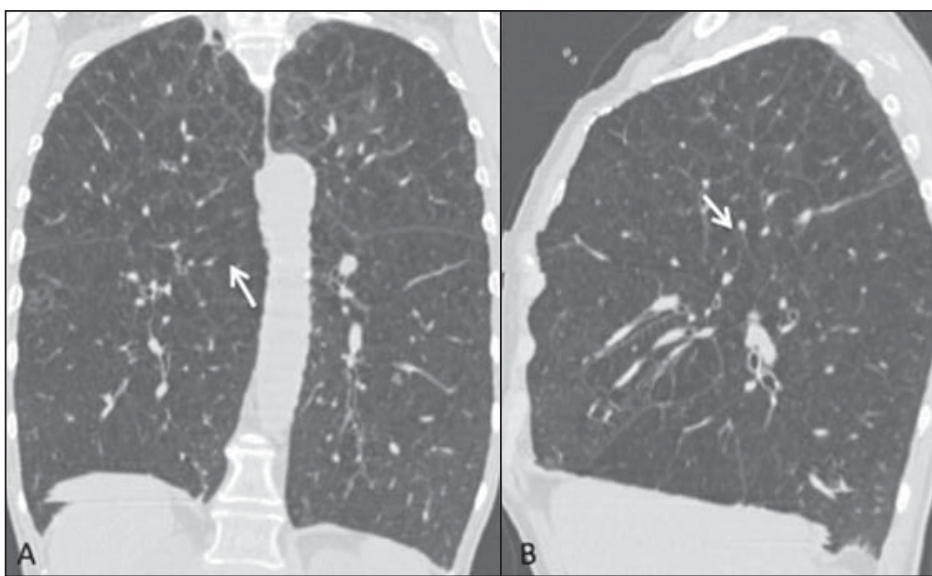

Figure 1. CT images (lung window) of a patient submitted to EBV implantation, with incomplete fissures and negative treatment response. In coronal (A), sagittal (B) and transversal (C) images it is possible to identify (arrows) the incomplete right oblique fissure (mean completeness of 50\%). Transversal post-treatment image (D) shows lack of atelectasis or signs of volume loss, with the fissure gap presenting the same aspect (arrow) and a valve adequately positioned in one of the right upper lobe bronchus (arrowhead).
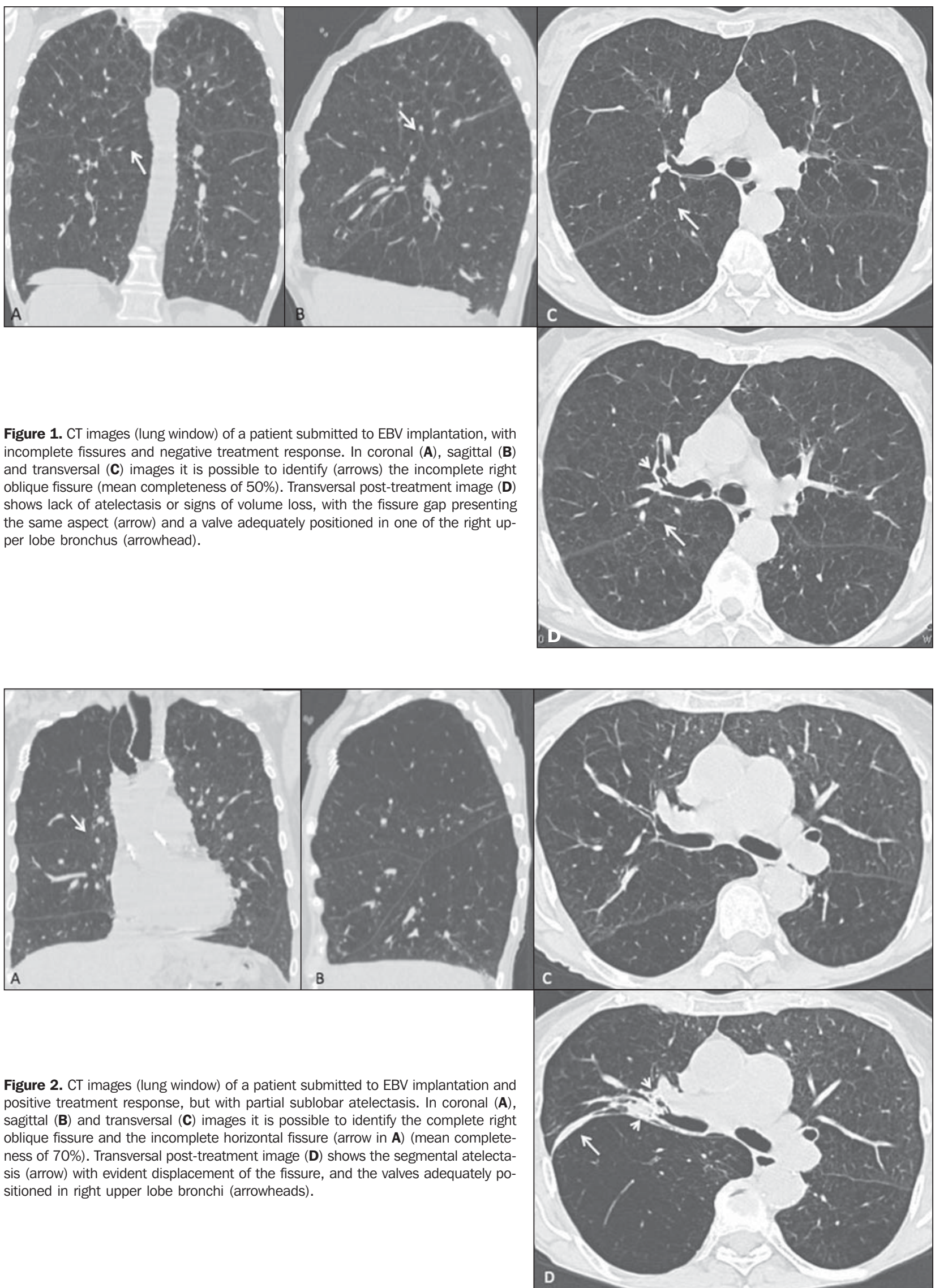

Figure 2. CT images (lung window) of a patient submitted to EBV implantation and positive treatment response, but with partial sublobar atelectasis. In coronal (A) sagittal (B) and transversal (C) images it is possible to identify the complete right oblique fissure and the incomplete horizontal fissure (arrow in A) (mean completeness of 70\%). Transversal post-treatment image (D) shows the segmental atelectasis (arrow) with evident displacement of the fissure, and the valves adequately positioned in right upper lobe bronchi (arrowheads). 

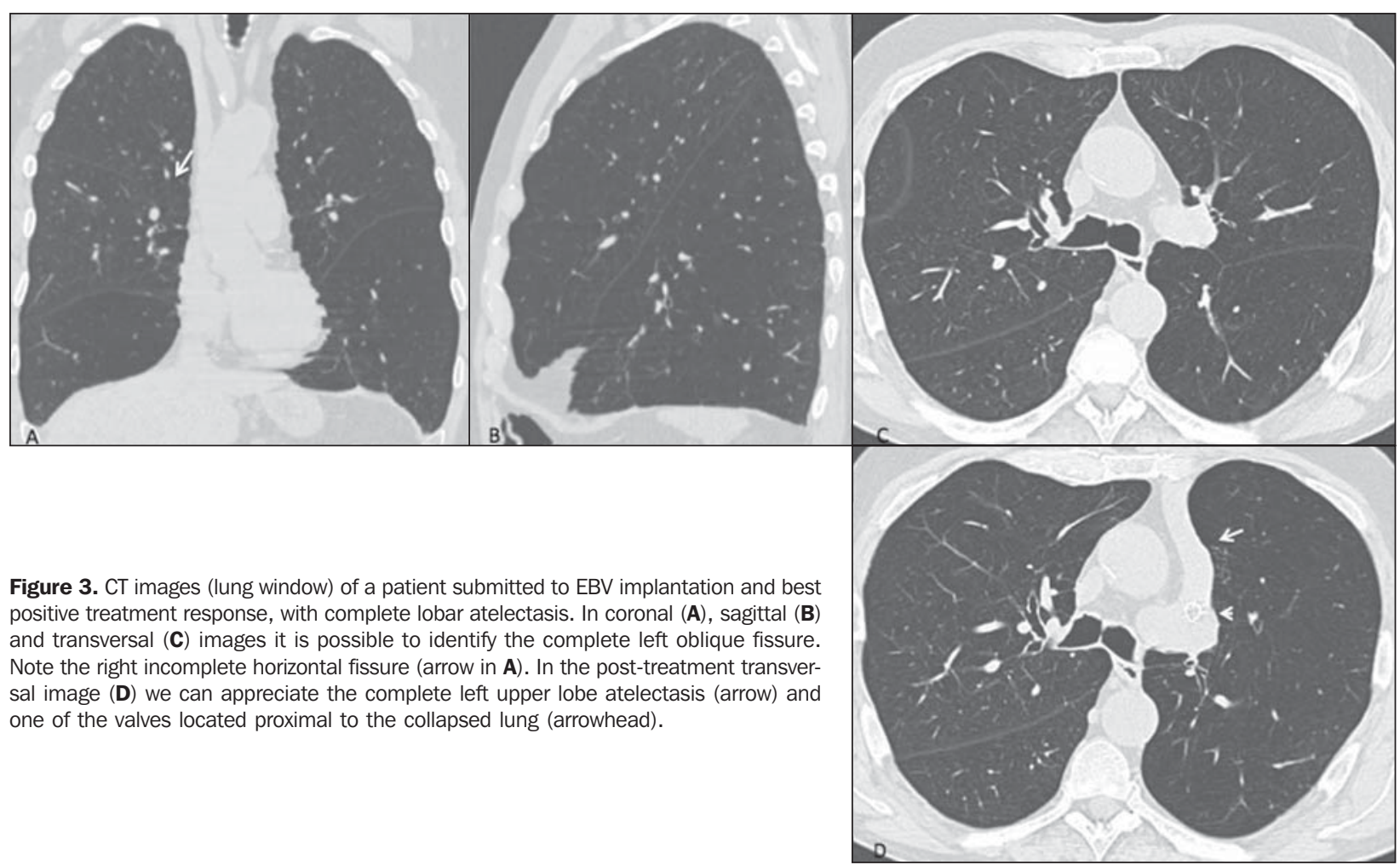

Figure 3. CT images (lung window) of a patient submitted to EBV implantation and best positive treatment response, with complete lobar atelectasis. In coronal $(\mathbf{A})$, sagittal $(\mathbf{B})$ and transversal (C) images it is possible to identify the complete left oblique fissure. Note the right incomplete horizontal fissure (arrow in A). In the post-treatment transversal image (D) we can appreciate the complete left upper lobe atelectasis (arrow) and one of the valves located proximal to the collapsed lung (arrowhead).

data or the QCTA, as expected for a uniform pre-treatment population. Analysis of the PFTs showed that post-treatment FEV1/ FVC was significantly increased $(p=$ $0.013)$, and RV\% ( $p=0.44)$ and TLC $\%$ ( $p$ $=0.029$ ) were significantly reduced only in the positive CT response group when compared to baseline; and comparison between the groups also showed that the FEV1/FVC was higher $(p=0.007)$ and RV\% was lower $(p=0.04)$ in this group compared to the negative CT response group (Table 2). The QCTA considering both lungs showed a reduced post-treatment total $\mathrm{LV}$ (mean reduction of $542 \mathrm{ml}, 8.0 \%$; $p=0.0076$ ) only in the positive CT group, and again, when considered only the treated lung submitted to EBV implantation, it showed a more pronounced reduction of the LV (mean reduction of $700 \mathrm{ml}, 20.6 \% ; p=0.0002)$ and EV (mean $331.4 \mathrm{ml}, 20.1 \%$; $p=0.013$ ) when compared with baseline, and a lower LV ( $p=0.005)$ when compared to the negative CT response group. The treated lung analysis also showed a less pronounced but significant reduction of the LV (mean $130.6 \mathrm{ml}, 3.6 \%$; $p=0.026$ ) in the negative CT group when compared with baseline (Table 2). Figure 4 shows an example of YACTA QCTA of emphysema.

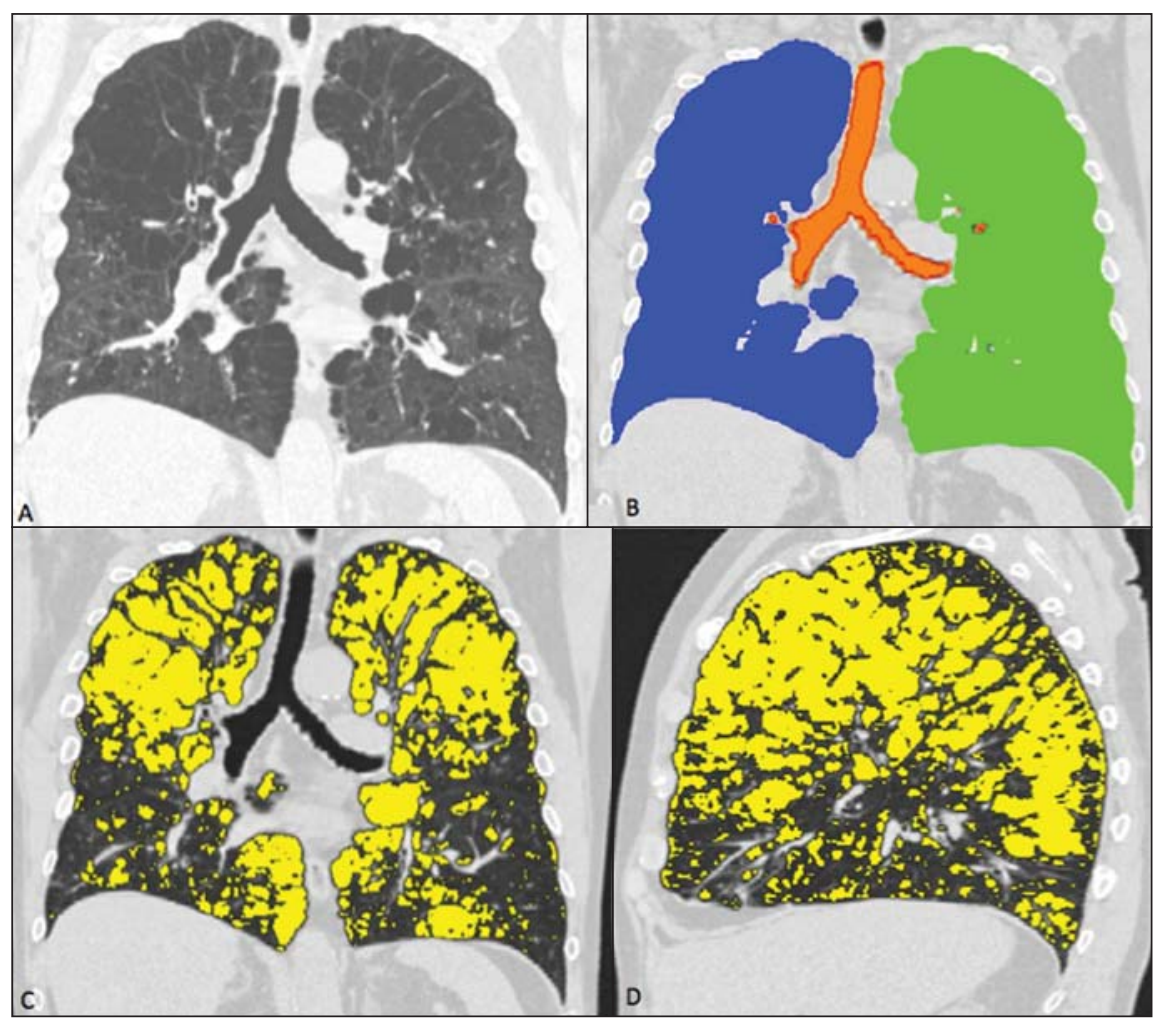

Figure 4. Example of the quantitative CT analysis done with the fully automated in-house software YACTA. In A we show a coronal reconstructed image (lung window) of one patient with severe heterogeneous emphysema previously to EBV implantation. The software provides superimposed images showing the segmentation (in $\mathbf{B}$, right lung in blue, left lung in green and tracheobronchial tree in orange) and the emphysema detection (C and $\mathbf{D}$, areas of emphysema in yellow, threshold of $-950 \mathrm{HU}$ ). Note the large involvement of both lungs (emphysema index of 44.3\%) and the upper lobe predominance, in the coronal (C) and sagittal (D) planes. 
Table 2 Mean values of the pulmonary function tests and quantitative CT analysis of emphysema performed with YACTA software, for all patients and distributed between the two groups, negative and positive CT response, for both lungs and only in the lung submitted to EBV implantation, before and after treatment.

\begin{tabular}{|c|c|c|c|c|c|c|c|c|}
\hline & & \multicolumn{7}{|c|}{ Pulmonary function tests } \\
\hline & & FVC (L) & FEV1 (L) & FEV1 & (\%) & & /\% & $\mathrm{TLC} \%$ \\
\hline \multirow{2}{*}{ All patients } & Pre-treatment & $2.45 \pm 0.86$ & $0.80 \pm 0.28$ & \multirow{2}{*}{\multicolumn{2}{|c|}{$\begin{array}{l}33.6 \pm 5.0 \\
34.7 \pm 8.0\end{array}$}} & \multicolumn{2}{|c|}{$241.3 \pm 48.7$} & $136.4 \pm 20.4$ \\
\hline & Post-treatment & $2.56 \pm 1.03$ & $0.86 \pm 0.35$ & & & & \pm 65.5 & $133.3 \pm 18.4$ \\
\hline \multirow{2}{*}{ Negative CT group } & Pre-treatment & $2.30 \pm 0.74$ & $0.72 \pm 0.25$ & \multirow{2}{*}{\multicolumn{2}{|c|}{$\begin{array}{l}31.5 \pm 3.1 \\
30.3 \pm 6.0\end{array}$}} & \multirow{2}{*}{\multicolumn{2}{|c|}{$\begin{array}{l}254.3 \pm 56.0 \\
261.5 \pm 77.3\end{array}$}} & $137.1 \pm 27.1$ \\
\hline & Post-treatment & $2.43 \pm 0.88$ & $0.73 \pm 0.28$ & & & & & $139.4 \pm 22.5$ \\
\hline \multirow{4}{*}{ Positive CT group } & Pre-treatment & $2.57 \pm 0.95$ & $0.87 \pm 0.30$ & \multirow{2}{*}{\multicolumn{2}{|c|}{$\begin{array}{c}35.2 \pm 5.8 \\
38.3 \pm 7.7^{*, \dagger}\end{array}$}} & \multirow{2}{*}{\multicolumn{2}{|c|}{$\begin{array}{c}230.8 \pm 40.6 \\
207.9 \pm 43.0^{*, \dagger}\end{array}$}} & $135.9 \pm 13.7$ \\
\hline & Post-treatment & $2.66 \pm 1.16$ & $0.97 \pm 0.37$ & & & & & $128.4 \pm 13.0^{*}$ \\
\hline & & \multicolumn{7}{|c|}{ QCTA - Both lungs } \\
\hline & & $\mathrm{LV}(\mathrm{ml})$ & EV ( & & & & MLD (HU) & 15th $(\mathrm{HU})$ \\
\hline \multirow{2}{*}{ All patients } & Pre-treatment & $7068.3 \pm 1547.4$ & \multirow{2}{*}{\multicolumn{2}{|c|}{$\begin{array}{l}3070.0 \pm 1139.7 \\
2992.4 \pm 1219.6\end{array}$}} & \multirow{2}{*}{\multicolumn{2}{|c|}{$\begin{array}{c}42.4 \pm 9.7 \\
43.4 \pm 11.1\end{array}$}} & $-878 \pm 13$ & $-982 \pm 12$ \\
\hline & Post-treatment & $6683.3 \pm 1472.0^{*}$ & & & & & $-878 \pm 18$ & $-982 \pm 12$ \\
\hline \multirow{2}{*}{ Negative CT group } & Pre-treatment & $7296.7 \pm 994.4$ & \multirow{2}{*}{\multicolumn{2}{|c|}{$\begin{array}{l}3146.7 \pm 754.2 \\
3180.8 \pm 928.4\end{array}$}} & \multirow{2}{*}{\multicolumn{2}{|c|}{$\begin{array}{l}43.2 \pm 8.6 \\
44.5 \pm 9.9\end{array}$}} & $-877 \pm 10$ & $-983 \pm 10$ \\
\hline & Post-treatment & $7104.9 \pm 1103.4$ & & & & & $-879 \pm 15$ & $-984 \pm 10$ \\
\hline \multirow{4}{*}{ Positive CT group } & Pre-treatment & $6882.7 \pm 1896.5$ & \multirow{2}{*}{\multicolumn{2}{|c|}{$\begin{array}{l}3007.7 \pm 1400.1 \\
2839.3 \pm 1425.3\end{array}$}} & \multirow{2}{*}{\multicolumn{2}{|c|}{$\begin{array}{l}41.8 \pm 10.7 \\
42.5 \pm 12.4\end{array}$}} & $-878 \pm 16$ & $-981 \pm 13$ \\
\hline & Post-treatment & $6340.7 \pm 1670.7^{*}$ & & & & & $-877 \pm 20$ & $-980 \pm 14$ \\
\hline & & \multicolumn{7}{|c|}{ QCTA - EBV lung only } \\
\hline & & LV (ml) & EV ( & & & & MLD (HU) & 15th $(\mathrm{HU})$ \\
\hline \multirow{2}{*}{ All patients } & Pre-treatment & $3497.7 \pm 827.4$ & \multirow{2}{*}{\multicolumn{2}{|c|}{$\begin{array}{c}1695.6 \pm 699.4 \\
1505.6 \pm 747.2^{*}\end{array}$}} & \multirow{2}{*}{\multicolumn{2}{|c|}{$\begin{array}{l}47.0 \pm 11.2 \\
46.7 \pm 14.2\end{array}$}} & $-884 \pm 15$ & $-985 \pm 12$ \\
\hline & Post-treatment & $3053.0 \pm 860.9 *$ & & & & & $-880 \pm 22$ & $-984 \pm 15$ \\
\hline \multirow{2}{*}{ Negative CT group } & Pre-treatment & $3628.2 \pm 619.9$ & \multirow{2}{*}{\multicolumn{2}{|c|}{$\begin{array}{l}1757.4 \pm 558.6 \\
1741.2 \pm 607.7\end{array}$}} & \multirow{2}{*}{\multicolumn{2}{|c|}{$\begin{array}{l}47.8 \pm 11.4 \\
48.9 \pm 12.1\end{array}$}} & $-884 \pm 14$ & $-986 \pm 13$ \\
\hline & Post-treatment & $3497.6 \pm 656.4^{*}$ & & & & & $-885 \pm 17$ & $-987 \pm 12$ \\
\hline \multirow{2}{*}{ Positive CT group } & Pre-treatment & $3391.6 \pm 971.5$ & \multirow{2}{*}{\multicolumn{2}{|c|}{$\begin{array}{c}1645.5 \pm 810.9 \\
1314.1 \pm 812.0^{*}\end{array}$}} & \multirow{2}{*}{\multicolumn{2}{|c|}{$\begin{array}{l}46.3 \pm 11.4 \\
44.9 \pm 15.9\end{array}$}} & $-883 \pm 16$ & $-984 \pm 12$ \\
\hline & Post-treatment & $2691.6 \pm 853.2^{*, \dagger}$ & & & & & $-876 \pm 25$ & $-981 \pm 16$ \\
\hline
\end{tabular}

FVC, forced vital capacity; FEV1, forced expiratory volume 1 second; FEV1/FVC, Tiffeneau index; RV\%, predicted residual volume; TLC\%, predicted total lung capacity; LV, lung volume; EV, emphysema volume; El, emphysema index; MLD, mean lung density; 15th, fifteenth percentile; QCTA, quantitative computed tomography analysis.

* Significantly different $(p<0.05)$ from baseline (pre-treatment); ${ }^{\dagger}$ significantly different $(p<0.05)$ from negative CT group.

\section{DISCUSSION}

EBV represent a new treatment modality for symptoms palliation in patients with severe emphysema, with fewer complications when compared to LVRS. It has been recently shown that better treatment results with EBV are obtained in patients with heterogeneous emphysema who have complete pulmonary fissures and that present lobar occlusion (collapse) after the valves implantation, as assessed by $\mathrm{HRCT}^{(\boldsymbol{9})}$. In this study we quantified interlobar fissures completeness in a group of patients submitted to EBV treatment, and showed that in the subgroup without CT visual response (lack of atelectasis or lobar volume loss), not only the prevalence of incomplete fissures in the treated lung was higher, but also the degree of incompleteness was higher when compared to the group with a positive CT response. We also demon- strated that a fully automated software for emphysema QCTA was able to detect the alterations after EBV implantation, without the need of any user interference or fissures delineation, with good conspicuity for the presence of atelectasis and volume loss, especially when considering the LV analysis only on the treated lung.

Emphysema is a highly prevalent and irreversible disease, and although some patients may benefit from pharmacological treatment and pulmonary rehabilitation, many remain significantly disabled, especially those with severe disease ${ }^{(\mathbf{1 0})}$. The benefits of LVRS in appropriately selected patients were demonstrated, but with high treatment associated morbidity and mortality, which led to the development of different less invasive bronchoscopic strategies $^{(11)}$. These methods include the placement of EBV, endobronchial coils, scarring biological agents, thermal vapor ablation and also airway bypass mechanisms ${ }^{(\mathbf{1 2}-14)}$ EBV are removable devices, implanted in the target bronchus using a flexible delivery catheter guided by the bronchoscope. They allow air and secretions to escape from the occluded lobe on expiration but prevent air from entering on inspiration, resulting in atelectasis of the target lobe, thereby allowing re-expansion of the adjacent less diseased lobe. Significant benefit was described with the use of EBV when compared to best medical care, with lower risks when compared to $\mathrm{LVRS}^{(\mathbf{5})}$. A limitation of this technique is the presence of incomplete interlobar fissures, which indicates the presence of interlobar collateral ventilation. Collateral channels are also present in the normal lung, but gain importance in the context of airways obstruction (COPD). When the fissures are incomplete, occlusion of all segmental bronchi will not isolate the target lobe, because air can still 
enter through these channels from adjacent non-treated lung, and adequate collapse does not occur ${ }^{(15)}$.

Many studies using different methods have already demonstrated that the interlobar fissures are highly variable among individuals and are frequently incomplete, but they differ greatly in regard to the incomplete fissures' prevalence and its relation to lung diseases and emphysema ${ }^{(\mathbf{1 6})}$. Degree of incompleteness is also variable, ranging from just short gaps of few centimeters to almost complete absence. It is well known that incomplete fissures may facilitate the spread of diseases, may affect the distribution of pleural effusion and must be addressed in surgical lobectomies, but the fissures status has recently gained renewed attention after description of its importance for the BLVR therapies ${ }^{(5)}$. Interlobar fissures are mostly commonly evaluated with HRCT. Our group has recently described that the clinical routine visual analysis of the fissures integrity can be done with a good degree of confidence and agreement in MDCT images, even in patients with severe emphysema who have small fissures gaps, but experienced readers might be required, as well as the help of MPR (sagittal and coronal images) ${ }^{(\mathbf{1 7})}$. Automatic tools for fissures delineation and quantification have also been described, suggesting that the use of the computerized method should act as a support aid for the visual reading done by the radiologist ${ }^{(\mathbf{1 8})}$. We still believe that the automatic analysis of the fissures completeness needs further refinement before routine clinical use, especially when considering the higher degree of incompleteness seen in COPD patients and the great anatomic distortions related to parenchymal destruction and presence of bullae. In this study we used a consensual visual reading and a 5\% increment estimation of the fissures completeness, similarly to what was recently described for patients submitted to bronchoscopic thermal vapor ablation ${ }^{(\mathbf{1 9})}$. With this approach, we could semi quantitatively demonstrate that not only the prevalence of incomplete fissures is different between groups of patients with and without radiological response after EBV implantation, but also that the degree of incompleteness was higher in the group of patients that showed no response after placement of the valves in the target lobe.

Lung volumes and densities measured with CT are now playing key roles in clinical trials of COPD therapies. Thoracic QCTA provides important complementary information to pulmonary function tests, because it allows assessment of both whole and regional disease ${ }^{(\mathbf{2 0})}$. QCTA has already been used to detect alterations related to BLVR therapies, and correlation of imaging findings and volume changes with clinical post-treatment outcome was described $^{(\mathbf{5 , 2 1 , 2 2 )}}$. It was previously demonstrated that some patients submitted to BLVR therapies with clinical improvement did not exhibit atelectasis or total lung volume reduction ${ }^{(\mathbf{2 3})}$, but more recently, the aids and superior results related to the presence of atelectasis and target lobe volume loss were confirmed, including a survival benefit ${ }^{(\mathbf{1 5 , 2 4 )}}$. In general, most authors described that the target lobe volume change was inversely correlated with changes in FEV1, and that expansion of healthier lung (ipsilateral and contralateral) contributed to the improvements in function parameters. In most studies, the lobar segmentation was performed in a semi-automatic fashion, with the need of a reader to delin-

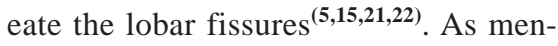
tioned before, this can be troublesome and time consuming, especially in cases of severe heterogeneous emphysema. In our study we used a fully automated tool for emphysema QCTA (YACTA software), which was able to detect the alterations after EBV implantation, with no need of any user interference. In disagreement to what was previously described ${ }^{(21)}$, we found significant differences in total lungs volume after EBV implantation. Furthermore, we found most significant differences when considering only the treated lung volume (side of EBV implantation), more pronouncedly reduced in the positive CT response group post-treatment exams, which also presented improvement in the PFTs. Therefore, we demonstrated that this QCTA technique could differentiate the cases with and without radiological response after EBV implantation, with good conspicuity. The software could even detect small post-treatment volume differences in the group with negative CT visual response. We believe that this automatic tool could be used not only to quantify the volume alteration changes and objectively follow up patients submitted to BLVR therapies, but also help detect mild volume changes not amenable to reliable visual detection on CT scans.

Our study has some limitations that must be addressed. First, one must be aware that, despite the definite importance of the radiological response (presence of atelectasis and target lobe volume loss), decision regarding maintenance or not of the valves is based also in symptoms improvement, which can be assessed by different tests, such as the 6-minute walk test and the St George's Respiratory Questionnaire, which were not investigated in this study. Correlations between changes in PFTs and CT parameters were not scrutinized in this study too, since we believe this is already well demonstrated in the literature. We did a consensual reading of the fissure status, thus an interobserver agreement for this 5\% increment method was not evaluated. One must also consider some technical aspects when evaluating EBV therapy response, like the number and location of the valves. In our study we considered that all patients were submitted to the best option regarding target lobe isolation, also with adequate technical implantation of the valves. Finally, when considering volume measurements done with QCTA, breathing status during images acquisition is very important. Our exams were done with automatic standardized breathing commands, and even if the reproducibility of breath hold and lung volume measurements was confirmed in previous studies ${ }^{(\mathbf{2 5})}$, we analyzed routine images acquisition protocols and no special control for the degree of inspiratory breath-hold was used.

\section{Acknowledgement}

The first author (MKS) has received financial support through a postdoctoral scholarship from Capes Foundation, Ministry of Education of Brazil.

\section{REFERENCES}

1. Weder W, Tutic M, Bloch KE. Lung volume reduction surgery in nonheterogenous emphysema. Thorac Surg Clin. 2009;19:193-9.

2. Berger RL, Decamp MM, Criner GJ, et al. Lung volume reduction therapies for advanced emphysema: an update. Chest. 2010;138:407-17. 
3. de Oliveira HG, Macedo-Neto AV, John AB, et al Transbronchoscopic pulmonary emphysema treatment: 1-month to 24-month endoscopic follow-up. Chest. 2006;130:190-9.

4. Wei SC, Heitkamp DE, Teague SD, et al. Endobronchial valves: radiographic appearance of a new device for lung volume reduction. AJR Am J Roentgenol. 2007;189:W92-3.

5. Sciurba FC, Ernst A, Herth FJ, et al. A randomized study of endobronchial valves for advanced emphysema. N Engl J Med. 2010;363:1233-44.

6. Cooper JD, Trulock EP, Triantafillou AN, et al. Bilateral pneumectomy (volume reduction) for chronic obstructive pulmonary disease. J Thorac Cardiovasc Surg. 1995;109:106-16.

7. Fishman A, Martinez F, Naunheim K, et al.; National Emphysema Treatment Trial Research Group. A randomized trial comparing lung-volume-reduction surgery with medical therapy for severe emphysema. N Engl J Med. 2003;348: 2059-73.

8. Heussel CP, Herth FJF, Kappes J, et al. Fully automatic quantitative assessment of emphysema in computed tomography: comparison to pulmonary function testing and normal values. Eur Radiol. 2009;19:2391-402.

9. Hopkinson NS, Toma TP, Hansell DM, et al. Effect of bronchoscopic lung volume reduction on dynamic hyperinflation and exercise in emphysema. Am J Respir Crit Care Med. 2005;171: 453-60.

10. Dodd JW, Hogg L, Nolan J, et al. The COPD as sessment test (CAT): response to pulmonary re- habilitation. A multicentre, prospective study. Thorax. 2011;66:425-9.

11. Criner GJ, Cordova F, Sternberg AL, et al. The National Emphysema Treatment Trial (NETT) Part II: Lessons learned about lung volume reduction surgery. Am J Respir Crit Care Med. 2011; 184:881-93.

12. Moore AJ, Cetti E, Haj-Yahia S, et al. Unilateral extrapulmonary airway bypass in advanced emphysema. Ann Thorac Surg. 2010;89:899-906.

13. Shah PL, Slebos DJ, Cardoso PFG, et al. Bronchoscopic lung-volume reduction with Exhale airway stents for emphysema (EASE trial): randomised, sham-controlled, multicentre trial. Lancet. 2011; 378:997-1005.

14. Snell G, Herth FJF, Hopkins P, et al. Bronchoscopic thermal vapour ablation therapy in the management of heterogeneous emphysema. Eur Respir J. 2012;39:1326-33.

15. Herth FJ, Noppen M, Valipour A, et al. Efficacy predictors of lung volume reduction with Zephyr valves in a European cohort. Eur Respir J. 2012; 39:1334-42.

16. Higuchi T, Reed A, Oto T, et al. Relation of interlobar collaterals to radiological heterogeneity in severe emphysema. Thorax. 2006;61:409-13.

17. Koenigkam-Santos M, Puderbach M, Gompelmann D, et al. Incomplete fissures in severe emphysematous patients evaluated with MDCT: incidence and interobserver agreement among radiologists and pneumologists. Eur J Radiol. 2012;81:4161-6.

18. van Rikxoort EM, Goldin JG, Galperin-Aizenberg
M, et al. A method for the automatic quantification of the completeness of pulmonary fissures: evaluation in a database of subjects with severe emphysema. Eur Radiol. 2012;22:302-9.

19. Gompelmann D, Heussel CP, Eberhardt R, et al. Efficacy of bronchoscopic thermal vapor ablation and lobar fissure completeness in patients with heterogeneous emphysema. Respiration. 2012; 83:400-6.

20. Brown MS, McNitt-Gray MF, Goldin JG, et al Automated measurement of single and total lung volume from CT. J Comput Assist Tomogr. 1999; 23:632-40.

21. Coxson HO, Nasute Fauerbach PV, Storness-Blis $\mathrm{C}$, et al. Computed tomography assessment of lung volume changes after bronchial valve treatment. Eur Respir J. 2008;32:1443-50.

22. Brown MS, Kim HJ, Abtin FG, et al. Emphysema lung lobe volume reduction: effects on the ipsilateral and contralateral lobes. Eur Radiol. 2012; 22:1547-55

23. Wood DE, McKenna RJ Jr, Yusen RD, et al. A multicenter trial of an intrabronchial valve for treatment of severe emphysema. J Thorac Cardiovasc Surg. 2007;133:65-73.

24. Hopkinson NS, Kemp SV, Toma TP, et al. Atelectasis and survival after bronchoscopic lung volume reduction for COPD. Eur Respir J. 2011;37: 1346-51.

25. Brown MS, Kim HJ, Abtin F, et al. Reproducibility of lung and lobar volume measurements using computed tomography. Acad Radiol. 2010; $17: 316-22$. 